Received: 18 January 2017

Accepted: 19 May 2017

Published online: 05 July 2017

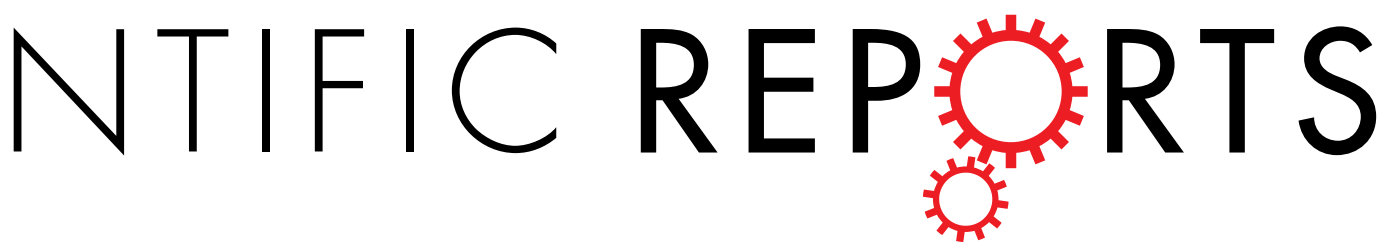

\title{
Role of biochar in biodegradation of nonylphenol in sediment: Increasing microbial activity versus decreasing bioavailability
}

Guanghuan Cheng ${ }^{1,2}$, Mingyang Sun ${ }^{1}$, Jingrang Lu ${ }^{3}$, Xinlei Ge ${ }^{1}$, Huihui Zhang ${ }^{2}$, Xinhua Xu ${ }^{2}$, Liping Lou' \& Qi Lin²

The observed strong sorption of hydrophobic organic contaminants (HOCs) to biochar presents potential implications for HOCs bioavailability and bioaccessibility in sediments, while biochar could impact sediment microbial ecology. However, the comprehensive study on the effects of biochar on HOC biodegradation coupled with bioavailability and microbial ecology are rarely documented. In this paper, the effects of biochar on the biodegradation of nonylphenol (NP) were investigated using 3 different NP concentrations $(20,50$ and $500 \mathrm{mg} / \mathrm{Kg})$ in sediments amended with different percentage of rice straw biochar (RC). Results showed that the influence of RC on NP biodegradation varied with different NP concentrations. At low NP concentrations, RC suppressed NP biodegradation by reducing NP bioavailability, while at high NP concentrations, moderate RC addition promoted biodegradation by reducing toxicity of NP to microbes. The effects of NP on microbial community structures were significant $(P<0.01)$, but those of RC were not significant $(P>0.05)$. The RC affected microorganisms through altering NP toxicity, microbial quantity and activity, but not microbial community structures. This study indicated that there could be an optimal biochar percentage in biochar-sediment systems at different $\mathrm{HOC}$ concentrations, which strengthened HOC biodegradation process and accelerated biodegradation rate, forming adsorption-biodegradation coupled bioremediation.

The ability of biochar to sorb in a nonlinear fashion to hydrophobic organic contaminants (HOCs) is well established ${ }^{1,2}$. Much of current research has emphasized the important role of carbonaceous materials in reducing contaminant aqueous availability and, consequently, biodegradation and/or bioaccumulation of sediment-bound contaminants, for the purpose of remediation ${ }^{3-5}$. Sopeña et al. ${ }^{6}$ demonstrated how HOC desorption processes in the presence of biochar are intimately related to HOC biodegradation by the indigenous sediment/soil microbiota.

Biochar can not only reduce HOC bioavailability in sediments/soils but also affect the fate of metabolites. Since HOC are biologically active molecules, they can potentially exert toxicity to non-target organisms within the sediment. Some HOC have been shown to have a range of short-term impacts on sediment/soil microbial communities, including reduction of biomass and altered community composition and function ${ }^{7}$. Since biochar reduces HOC bioavailability in sediments/soils, an application of biochar to sediments could reduce ecotoxicological impacts of HOC. Additionally, the effects of biochar on microbes have shown that biochar provides microbial refuges or nutrients to improve sediment microbial biomass and/or microbial activity due to its porous nature and abundance of the elements of $\mathrm{C}, \mathrm{N}$ and $\mathrm{P}^{8,9}$. Thus, the implication of biochar on HOC biodegradation in sediment involves two functions as it impacts HOC bioavailability and microbial activity. However, how the impacts of biochar occur on both HOC bioavailability and microbial activity in sediment is not clear.

Previous studies on the effects of biochar on the biodegradation of HOC focused mainly on HOC bioavailability ${ }^{3-5}$. For example, Rhodes et al. ${ }^{5}$ found that activated carbon (AC) depressed the mineralization of phenanthrene

${ }^{1}$ Jiangsu Key Laboratory of Atmospheric Environment Monitoring and Pollution Control (AEMPC), School of Environmental Science and Engineering, Nanjing University of Information Science \&Technology, Nanjing, 210044, People's Republic of China. ${ }^{2}$ Department of Environmental Engineering, Zhejiang University, Hangzhou, 310029, People's Republic of China. ${ }^{3}$ Office of Research and Development, U.S. Environmental Protection Agency, Cincinnati, $\mathrm{OH}, 45220$, USA. Correspondence and requests for materials should be addressed to L.L. (email: loulp@zju.edu.cn) 


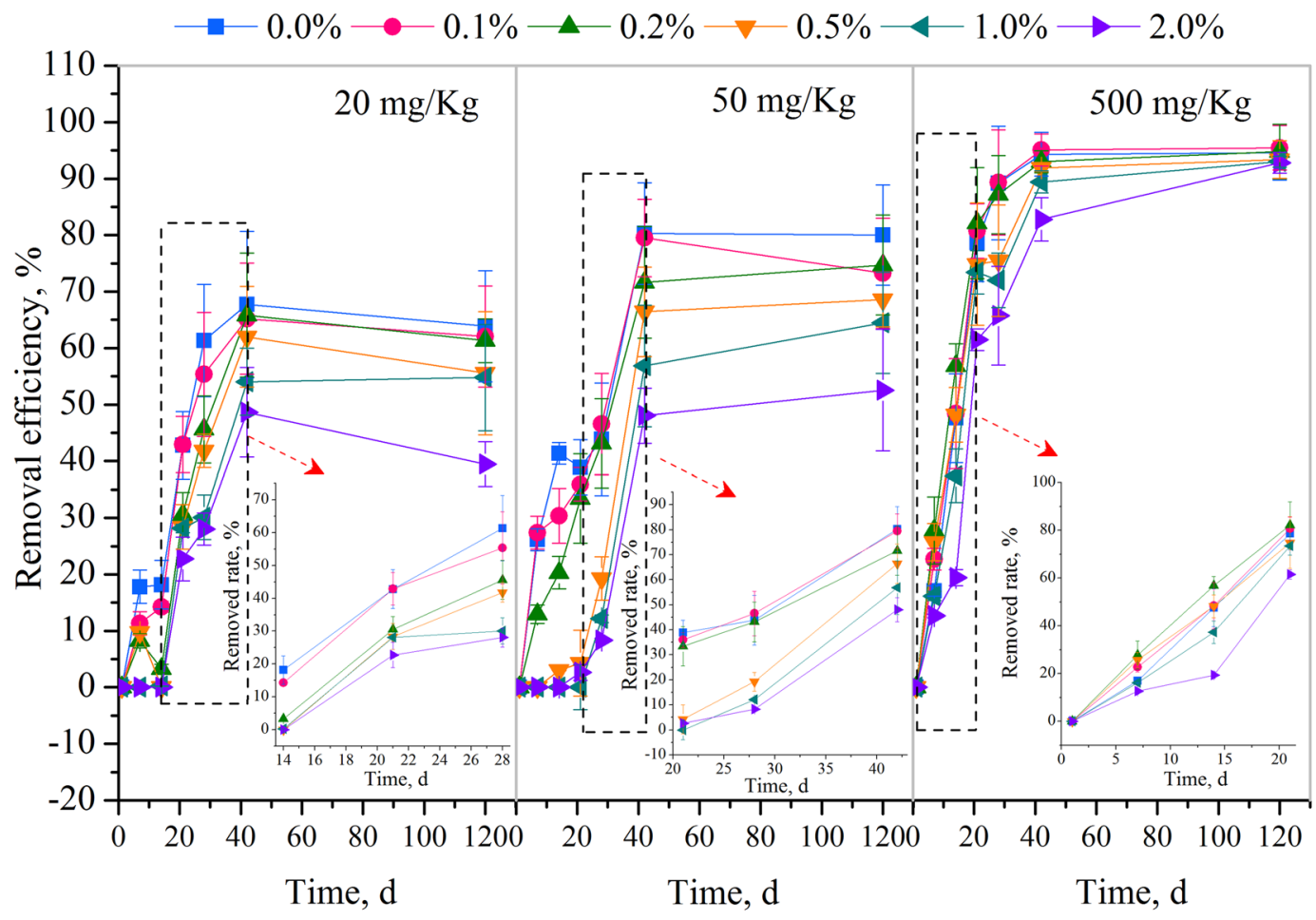

Figure 1. NP biodegradation curves in RC-sediment system with different RC percentages. NP rapid biodegradation period were marked with a dotted frame and showed in an enlarged figure for each NP concentration.

(PHE) in soil due to desorption inhibition. Yang et al. ${ }^{4}$ studied the effect of adding coal-derived AC to soil on PHE bioavailability to inoculated Mycobacterium vanbaalenii PYR-1. Compared to the unamended soils, the addition of $\mathrm{AC}$ at amounts of between $0.5 \%$ and $6 \%$ led to an increasing reduction in the amounts mineralized. However, there are only a few studies for using amendment in biochar matrix to impact HOC catabolic activity of the indigenous sediment/soil microflora. In those studies, the amendment showed positive effects of biochar on microbial degradation ${ }^{10,11}$. For example, Bushnaf et al. ${ }^{11}$ found that a $2.0 \%$ biochar amendment could accelerate polycyclic aromatic hydrocarbon (PAHs) biodegradation rate, while Vasilyeva et al..$^{10}$ reported that AC amendment accelerated biodegradation of 3,4-dichloroaniline (DCA) in sandy soils. AC promotes strong binding through accelerated microbial reduction of its nitro groups, catalytic chemical oxidation of the methyl group, and polymerization or binding of the products formed of 2,4,6-trinitrotoluene (TNT), due to a sharp reduction of the toxicity of these contaminated soils to microbes.

Previous research results concerning the impact of biochar on HOC biodegradation were contradictory. Overall, the impact of biochar on HOC biodegradation varied with different biochar percentages, HOC concentrations and microbial activity. Hence, in this study, the effects of rice straw biochar (RC) on nonylphenol (NP) biodegradation in sediment were investigated. In addition, aqueous available NP concentration, NP toxicity to microbes, microbial biomass/activity and microbial community structure were measured to explore impact of RC on NP availability and microbial ecology. To our knowledge, this is the first study to extensively investigate the role of biochar in NP biodegradation, and to understand the interactions among biochar, contaminants, and degrading microorganisms in sediments.

\section{Results and Discussion}

Biodegradation of NP in RC-sediment systems. The biodegradation of NP with starting concentrations of 20,50 and $500 \mathrm{mg} / \mathrm{Kg}$ after a $120 \mathrm{~d}$ incubation period at $25^{\circ} \mathrm{C}$ in the sediments with $0.0 \%, 0.1 \%, 0.2 \%$, $0.5 \%, 1.0 \%$, and $2.0 \% \mathrm{RC}$ are shown in Fig. 1 . There was a rapid biodegradation period during the NP biodegradation process (marked with a dotted frame and showed in an enlarged figure for each NP concentration in Fig. 1). In the rapid biodegradation stage, when the NP concentrations were at 20 and $50 \mathrm{mg} / \mathrm{Kg}$, the NP biodegradation ratio decreased with the increase of RC percentages $(P<0.01)$, while when the NP concentration was at $500 \mathrm{mg} / \mathrm{Kg}$, NP biodegradation ratios in $0.1 \%, 0.2 \%$ and $0.5 \% \mathrm{RC}$ amended sediment samples were higher than in the pure sediment samples $(P<0.01)$, in which there was no addition of biochar. When the RC percentages were $>0.5 \%$, NP biodegradation ratios also decreased with the increase of RC percentages $(P<0.01)$. However, with biodegradation processing into the slow biodegradation stage, the NP biodegradation ratios decreased with the increase of RC percentages $(0.01<P<0.05)$ at $500 \mathrm{mg} / \mathrm{Kg}$, at which, the biodegradation ratios were similar with those at low concentrations $(20$ and $50 \mathrm{mg} / \mathrm{Kg})$. 


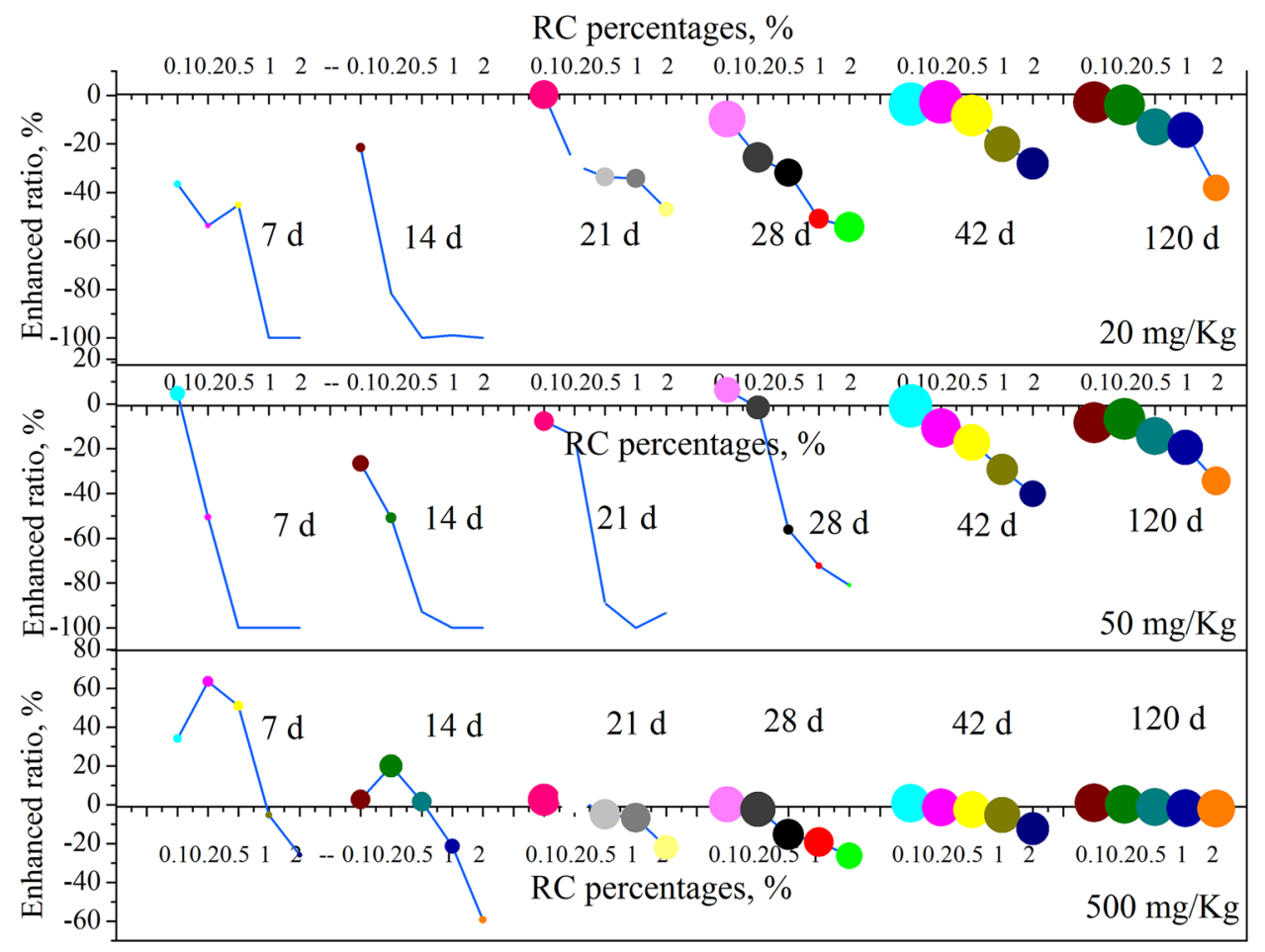

Figure 2. Impact of RC percentages on biodegradation of NP with different concentration in sediment. Enhancement ratio of RC on NP biodegradation was calculated by NP removal efficiency using pure sediment samples as blank control. 0.1, 0.2, 0.5, 1.0 and 2.0 in horizontal axis represent $0.1,0.2,0.5,1.0$ and $2.0 \%$ RC percentages in sediment, respectively. The size of color circles represents NP removal efficiency.

Impact of RC on biodegradation of NP in sediments. In order to examine the role of RC in NP biodegradation, an enhanced ratio of RC on NP biodegradation was calculated using pure sediment samples as blank controls (Fig. 2). Results showed that when NP concentrations were at 20 and $50 \mathrm{mg} / \mathrm{Kg}$, the enhanced ratio of RC at different RC percentages on NP biodegradation were all negative, indicating that amendment of RC reduced NP biodegradation at low NP concentrations, and the extent of reduction increased with raised RC percentages. It has been reported that increased sorption of HOCs by carbonaceous materials, such as activated carbon, charcoal and biochar, might induce a decrease in microbial degradation due to a reduction in bioaccessibility and bioavailability ${ }^{1,2,12,13}$. For example, a number of studies have demonstrated that even small amounts of a sediment/soil amendment, such as activated carbon, can reduce biodegradation due to its strong sorptive capacity and ability to increase the slowly and very slowly desorbing fractions leading to a reduced contaminant availability ${ }^{3-5}$.

When NP concentration was at $500 \mathrm{mg} / \mathrm{Kg}$, the enhanced ratios of $0.1 \%, 0.2 \%$ and $0.5 \% \mathrm{RC}$ amendment before $21 \mathrm{~d}$ on NP biodegradation were positive, suggesting that proper RC amendment promoted NP biodegradation at a high NP concentration. A similar result was observed by Vasilyeva et al. ${ }^{10}$ who found that $1.0 \%$ activated carbon could accelerate biodegradation of DCA and TNT with the high concentrations greater than $500 \mathrm{mg} / \mathrm{Kg}$, by reducing the toxicity of readily available chemicals in soil and transferring them to a less toxic soil fraction. However, in this study, even at NP concentrations of $500 \mathrm{mg} / \mathrm{Kg}$, a $1.0 \%$ or $2.0 \% \mathrm{RC}$ amendment reduced NP biodegradation, like at low NP levels.

A pseudo first order kinetics model (Formula (1)) was applied to fit NP biodegradation curves. Fitted parameters are listed in Table 1 . Both NP biodegradation fraction $\left(F_{\mathrm{de}}\right)$ and average biodegradation rate constant $\left(k_{\text {ave }}\right)$ decreased, while half-life period $\left(t_{1 / 2}\right)$ (Formula (2)) increased with the increase of RC percentages at low NP concentrations $(20$ and $50 \mathrm{mg} / \mathrm{Kg}$ ). This result indicated that RC suppressed NP biodegradation and slowed NP biodegradation, increased NP residue and extended NP residual time in sediment. At high NP concentration $(500 \mathrm{mg} / \mathrm{Kg})$, although $F_{\mathrm{de}}$ still trended to decrease with the increase of RC percentages, $k_{\text {ave }}$ seemed increase from 0 to $0.2 \% \mathrm{RC}$, then decreased from 0.2 to $2 \% \mathrm{RC}$, and obtained its $\max k_{\text {ave }}$ at $0.2 \% \mathrm{RC}$. The half-life of NP first decreased then increased, and reached to lowest value at $0.2 \% \mathrm{RC}$, indicating that the proper proportion of RC accelerated NP biodegradation at high NP concentration.

Mechanism of RC affecting biodegradation of NP in sediments. Effects of RC on NP concentrations in water soluble fraction of $R C$-sediment system. Previous studies indicated that only bioavailable contaminant can be utilized by organisms $s^{14,15}$ and it had been suggested that the free state of HOCs might provide a direct measure of the microbial degradable contaminant fraction ${ }^{16-18}$. NP concentrations in the water soluble fraction in sediments with different RC percentages were measured to examine the effects of RC on NP bioavailability (Fig. 3). For the sterilized samples, NP concentrations in water soluble fraction decreased with increasing RC percentages in all abiotic samples, indicating that RC reduced NP bioavailability due to its high affinity to NP. The 


\begin{tabular}{|l|l|l|l|l|l|l|l|}
\hline NP concentration & Parameters & $\mathbf{0 . 0} \%$ & $\mathbf{0 . 1} \%$ & $\mathbf{0 . 2} \%$ & $\mathbf{0 . 5} \%$ & $\mathbf{1 . 0 \%}$ & $\mathbf{2 . 0 \%}$ \\
\hline \multirow{5}{*}{$20 \mathrm{mg} / \mathrm{Kg}$} & $F_{\mathrm{de}}(\%)$ & 70.10 & 67.90 & 68.67 & 62.95 & 61.22 & 42.09 \\
\cline { 2 - 8 } & $k_{\text {ave }}(\% / \mathrm{d})$ & 0.047 & 0.044 & 0.032 & 0.031 & 0.026 & 0.027 \\
\cline { 2 - 8 } & $t_{1 / 2}(\mathrm{~d})$ & 14.88 & 15.83 & 22.00 & 22.15 & 26.76 & 25.77 \\
\cline { 2 - 8 } & $R^{2}$ & 0.657 & 0.658 & 0.609 & 0.552 & 0.643 & 0.582 \\
\hline \multirow{5}{*}{$50 \mathrm{mg} / \mathrm{Kg}$} & $F_{\mathrm{de}}(\%)$ & 83.02 & 79.18 & 80.97 & 81.94 & 77.12 & 72.99 \\
\cline { 2 - 8 } & $k_{\text {ave }}(\% / \mathrm{d})$ & 0.040 & 0.038 & 0.030 & 0.025 & 0.023 & 0.021 \\
\cline { 2 - 8 } & $t_{1 / 2}(\mathrm{~d})$ & 17.55 & 18.39 & 23.42 & 27.56 & 29.62 & 33.65 \\
\cline { 2 - 8 } & $R^{2}$ & 0.891 & 0.742 & 0.930 & 0.634 & 0.583 & 0.624 \\
\hline \multirow{5}{*}{$500 \mathrm{mg} / \mathrm{Kg}$} & $F_{\mathrm{de}}(\%)$ & 101.57 & 101.80 & 99.00 & 97.17 & 98.06 & 98.68 \\
\cline { 2 - 8 } & $k_{\text {ave }}(\% / \mathrm{d})$ & 0.055 & 0.058 & 0.066 & 0.056 & 0.047 & 0.035 \\
\cline { 2 - 8 } & $t_{1 / 2}(\mathrm{~d})$ & 12.56 & 11.99 & 10.53 & 12.45 & 14.87 & 19.92 \\
\cline { 2 - 8 } & $R^{2}$ & 0.929 & 0.945 & 0.967 & 0.972 & 0.936 & 0.907 \\
\hline
\end{tabular}

Table 1. Fitted parameters of biodegradation curves of NP in RC-sediment system.

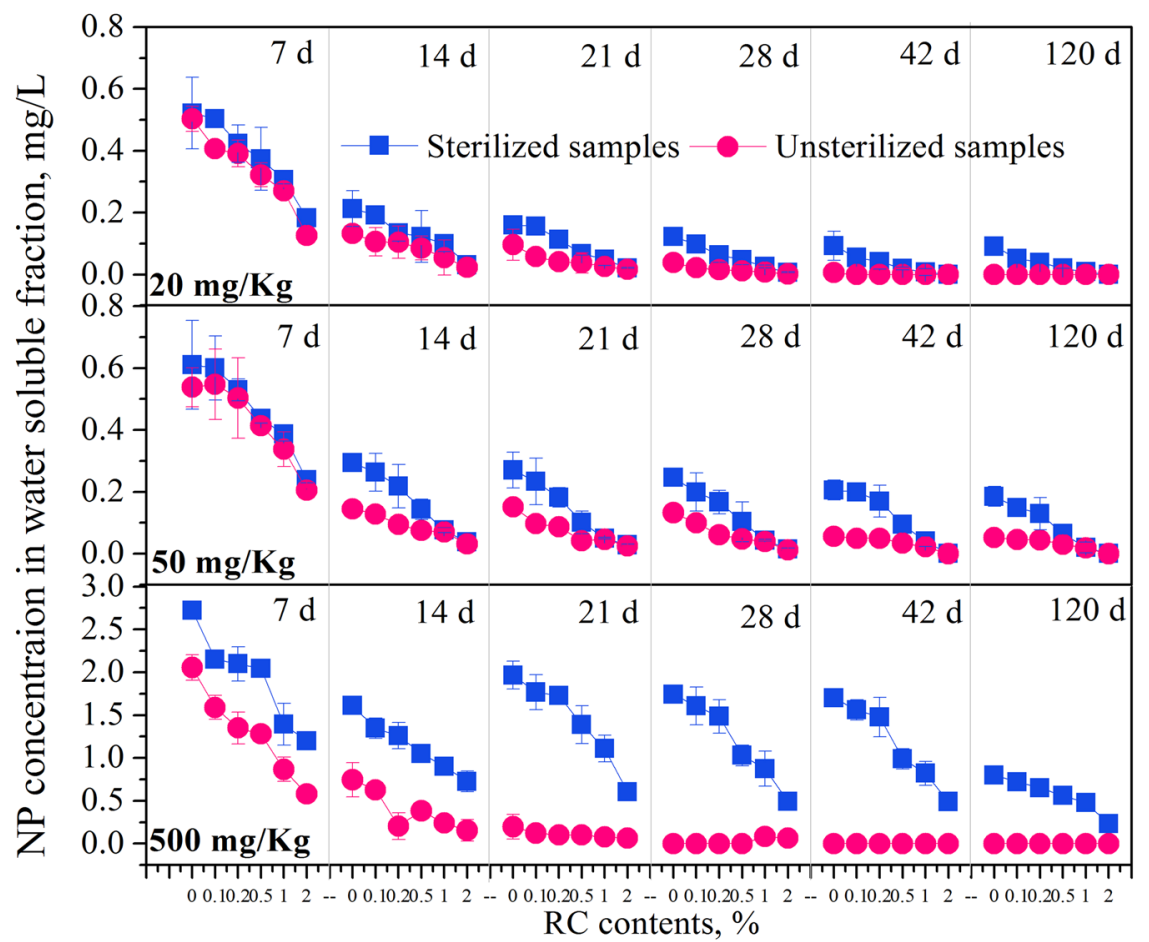

Figure 3. Changes of NP concentration in water soluble fraction with time in RC-sediment systems.

difference between sterilized and unsterilized samples, considered as the amount of NP biodegradation in the water soluble fraction, tended to decrease with increasing RC percentages in all samples, indicating RC depressed aquatic NP biodegradation by reducing NP bioavailability. In other studies, the application of carbonaceous amendments, such as AC, to sediment/soils also reduced both the rates and extent of HOC biodegradation due to the strong sorption ${ }^{3,5}$. Although the fact that strong affinity of RC to NP reduced free state NP (Fig. 3), it is worth noting that proper RC amendment promoted NP biodegradation at high NP concentrations (Fig. 2).

Effect of RC on NP toxicity to microbes. Since biochar reduced HOC bioavailability in the sediments mentioned above, the application of biochar to sediments could also reduce the toxicity of NP to organisms. To test this hypothesis, the toxicity of NP in the aquatic phase and sediments were both estimated using the luminescent bacterial toxicity testing method (Fig. 4A) and FDA hydrolytic activity assay (Fig. 4B). The luminous intensity of the aquatic phase increased for $\mathrm{NP}<3.0 \mathrm{mg} / \mathrm{L}$, and decreased for $\mathrm{NP}>3.0 \mathrm{mg} / \mathrm{L}$, indicating $\mathrm{NP}$ stimulated luminescent bacteria while NP concentrations were lower than $3.0 \mathrm{mg} / \mathrm{L}$ and NP was toxic to luminescent bacteria while NP concentrations were higher than $3.0 \mathrm{mg} / \mathrm{L}$ in aquatic phase. And in the biodegradation system, initial water soluble NP concentrations were $0.50,0.54$ and $4.52 \mathrm{mg} / \mathrm{L}$ for pure sediments with the NP concentrations of 20,50 and $500 \mathrm{mg} / \mathrm{Kg}$, respectively, suggesting that when the NP concentrations in sediments were low (20 and $50 \mathrm{mg} /$ $\mathrm{Kg}$ ), initial water soluble NP concentrations were lower than $3.0 \mathrm{mg} / \mathrm{L}$, so the RC amendment reduced stimulation 


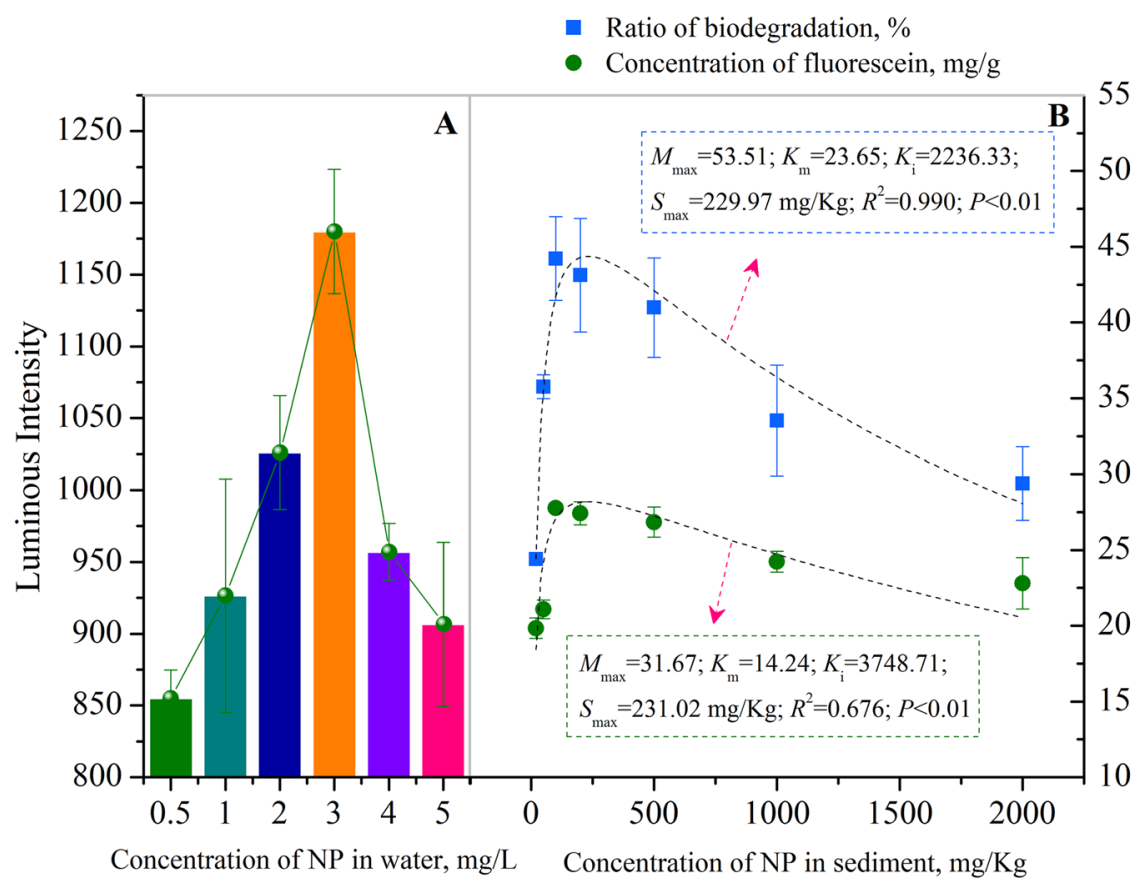

Figure 4. Toxicity of NP in aquatic phase and sediment phase respectively. (A) NP toxicity in aquatic phase to luminescent bacteria; (B) NP toxicity in sediment phase to FDA hydrolytic activity and NP biodegradation ratio.

of NP to bacterial activities. When the NP concentration in sediment was high $(500 \mathrm{mg} / \mathrm{Kg})$, NP initial water soluble concentration in the pure sediment was $4.52 \mathrm{mg} / \mathrm{L}$. The NP concentration was 3.55 and $2.98 \mathrm{mg} / \mathrm{L}$ in $0.1 \%$ and $0.2 \% \mathrm{RC}$ amendment, respectively, and the NP concentrations were all lower than $3.0 \mathrm{mg} / \mathrm{L}$ in $\geq 0.5 \% \mathrm{RC}$ amendments. Hence, the $0.1 \%$ and $0.2 \% \mathrm{RC}$ amendment reduced NP toxicity to bacteria and improved bacterial activities at $500 \mathrm{mg} / \mathrm{Kg}$ in sediment. However, $\geq 0.5 \% \mathrm{RC}$ amendment reduced or even depressed the stimulation of NP to bacterial activities in sediment.

In order to further examine the toxicity of NP to microbes, the impact of different concentrations of NP in the sediment phase on FDA hydrolytic activity and NP biodegradation ratios were examined (Fig. 4B). Both FDA hydrolytic activity and NP biodegradation ratios initially increased then decreased with increasing NP concentrations in sediments, indicating that there could be a threshold under which the increase of NP concentrations stimulated enzyme activity and promoted NP biodegradation, while above which NP caused toxicity to sediment microbes and depressed NP biodegradation. In order to get this threshold, the Haldane model was applied to fit these two sets of data. The fitted data showed that $M_{\max }$ was $53.51 \%$ and $31.67 \mathrm{mg} / \mathrm{g}$ for NP biodegradation rate and concentration of fluorescein, respectively with a corresponding NP concentration of $229.97 \mathrm{and} 231.02 \mathrm{mg} /$ $\mathrm{Kg}$, respectively, or approximately $230 \mathrm{mg} / \mathrm{Kg}$ for both. Consequently, $230 \mathrm{mg} / \mathrm{Kg}$ was identified as the NP toxic threshold value to sediment microbes. When the NP concentrations were 20 and $50 \mathrm{mg} / \mathrm{Kg}$ in the sediments, which were lower than $230 \mathrm{mg} / \mathrm{Kg}$, no toxic effect was observed to the microbes, but when the NP concentration was $500 \mathrm{mg} / \mathrm{Kg}$ in the sediments, the NP was toxic to sediment microbes. A similar result was also observed that while azoxystrobin reduced dehydrogenase activity, black carbon (BC) addition greatly increased dehydrogenase activity $^{6}$. However, even though $500 \mathrm{mg} / \mathrm{Kg} \mathrm{NP}$ exhibited toxicity to microbes, both the NP biodegradation ratio and concentrations of fluorescein were higher than when the NP concentrations were at 20 and $50 \mathrm{mg} / \mathrm{Kg}$.

Effect of RC on microbial quantity and activity in sediment. The qPCR method and FDA hydrolytic activity assay were applied to measure microbial quantities for all bacteria and enzymatic activity for biodegradation samples at 1,21 and $120 \mathrm{~d}$, respectively (Supplementary Figure S1). In the $21 \mathrm{~d}$ samples, when NP biodegradation rate was fastest (Supplementary Figure S2), both microbial quantities and enzymatic activity were higher than that in the 1 $\mathrm{d}$ and $120 \mathrm{~d}$ samples. This finding indicated that NP biodegradation can be influenced by microbial quantities and enzymatic activity. Microbial quantities and enzymatic activity in sediment samples with the NP concentration of $500 \mathrm{mg} / \mathrm{Kg}$ were higher than those in sediment samples with the NP concentrations of $20 \mathrm{and} 50 \mathrm{mg} / \mathrm{Kg}$. This suggests the NP concentration $(500 \mathrm{mg} / \mathrm{Kg}$ ) caused toxicity to microbes, but its stimulation was greater than that in low NP sediment $\left(20\right.$ and $50 \mathrm{mg} / \mathrm{Kg}$ ). This result is consistent with a study by Stenrad et al. ${ }^{19}$ and Jontofsohn et al. ${ }^{20}$. The former study found that NP promoted soil respiration, while the latter suggested that there were positive correlation between NP concentrations and bacterial cell numbers, and NP promoted increase of active bacteria. Similarly, it was found that the reduction of dehydrogenase activity by azoxystrobin was enhanced by BC addition ${ }^{6}$. 

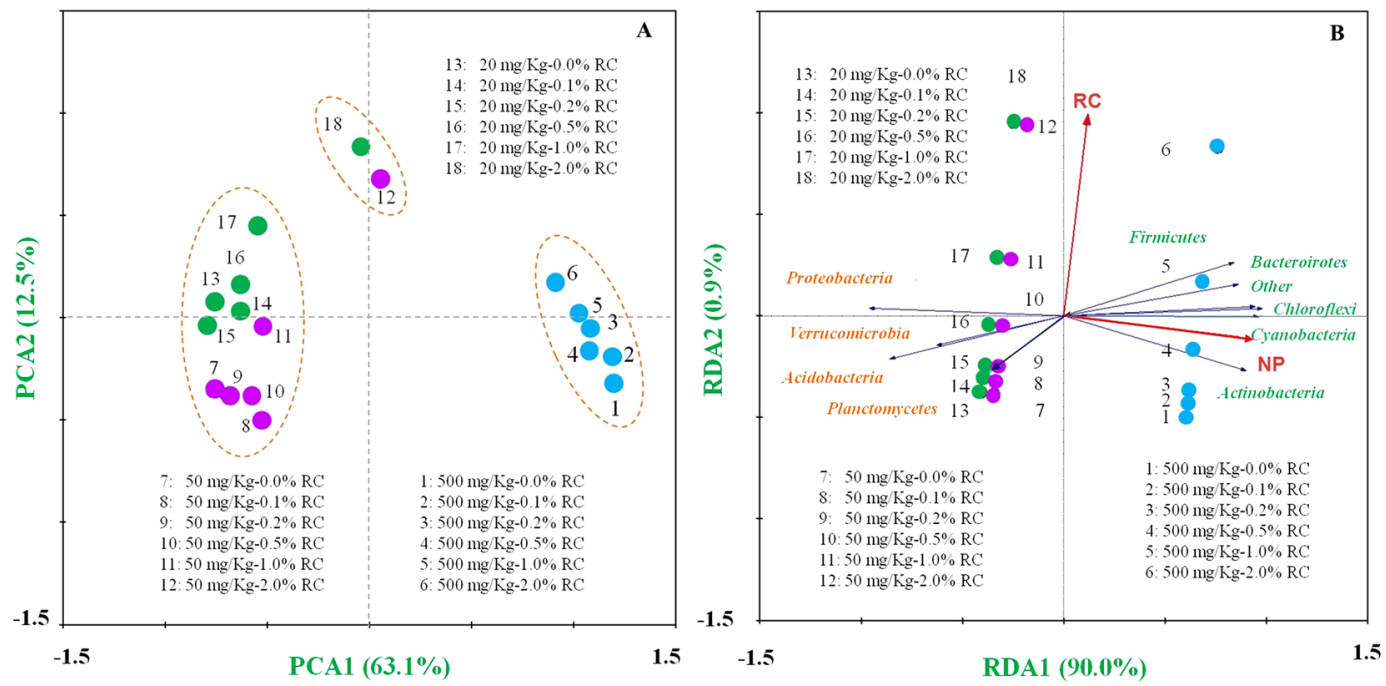

Figure 5. Cluster (A) and RDA (B) analysis at genus level.

Effect of RC on microbial community in sediments. Microbial community data in the pure sediment with different NP concentrations was illustrated in Supplementary Figure S3. The relationship of microbial community structures with NP concentrations and RC percentages was examined using PCA and RDA analysis at the genus level (Fig. 5). In the PCA analysis, $63.1 \%$ of the variance is explained by axis 1 and $12.5 \%$ by axis 2 . Axis 1 separates microbial community structures into the $500 \mathrm{mg} / \mathrm{kg} \mathrm{NP}$ group from the others $(20$ and $50 \mathrm{mg} / \mathrm{kg} \mathrm{NP}$ ), while axis 2 separates $2.0 \% \mathrm{RC}$ amendment from $<2 \% \mathrm{RC}$ amendment in the 20 to $50 \mathrm{mg} / \mathrm{kg} \mathrm{NP}$, indicating that NP was the main factor affecting microbial community structures. The first two axes of the RDA explained a high percentage of the variance $(90.9 \%)$. The permutation tests confirmed that NP concentrations were significantly associated with the change in bacterial community structures $(P<0.01)$, which were in agreement with previous reports that low level NP amendment had no or little impact on aquatic bacterial community structures ${ }^{19,20}$, but high level NP induced a significant shift in bacterial community structures ${ }^{21}$. For example, Stenrad et al. ${ }^{19}$ examined the impact of $10 \mathrm{mg} / \mathrm{Kg} \mathrm{NP}$ on soil community structures and suggested that there was not a significant inhibition or enhancement on soil community structures by NP, and Jontofsohn et al. ${ }^{20}$ found $0.162-2.014 \mathrm{mg} /$ $\mathrm{Kg}$ NP only slightly affected sediment microbial community structures. Wang et al. ${ }^{21}$ indicated that $150 \mathrm{mg} / \mathrm{Kg}$ significantly induced a shift of sediment microbial communities.

A number of studies previously suggested that biochar amendment could influence microbial community structure significantly ${ }^{22-24}$. For example, Tong et al..$^{24}$, Anderson et al. ${ }^{22}$ and Khodadad et al. ${ }^{23}$ all found that biochar could improve relative abundance of dominant microbial species. However, in this study, there was no significant association of $\mathrm{RC}$ with the bacterial community composition ( $P>0.05$ for each comparison). RC could indirectly, rather than directly, affect sediment microbial community structures through the effect of RC on NP biodegradation, bioavailability and toxicity.

Main functional microbial species in NP biodegradation system with RC amendment. Taxonomic identity of each phylotype was determined using the Ribosomal Database Project (RDP) Classifier. A total of 264,922 trimmed sequences with the length of $>200$ bp was obtained for 18 samples and 20476 operational taxonomic units (OTUs) with $97 \%$ similarity were identified. Microbial relative abundance $(>1 \%)$ was compared at genus level among NP concentrations and RC percentages (Fig. 6). The concentrations of NP induced a significant shift in bacterial community during incubation. The relative abundance of some bacterial species increased with NP concentrations, such as some of Proteobacteria (Pseudomonas, Methylophilus, Tolumonas, Dechloromonas and Zoogloea), Chloroflexi (Longilinea) and Bacteroidetes (Flavobacterium). Furthermore, when the NP concentration was $500 \mathrm{mg} / \mathrm{Kg}$, relative abundance of Pseudomonas was highest, while when NP at low level (20 and $50 \mathrm{mg} / \mathrm{Kg}$ ), relative abundance of Pseudomonas was low. Previous studies reported that Pseudomonas isolated from NP contaminated sediments as NP degrading bacteria and NP was considered as energy and carbon sources for this bacteria ${ }^{25,26}$. Wang et al. ${ }^{21}$ suggested that tolerance of Gammaproteobacteria, which the genus Pseudomonas belongs to, to NP was higher than $150 \mathrm{mg} / \mathrm{Kg}$. In this study, NP concentration was up to $500 \mathrm{mg} / \mathrm{Kg}$, indicating that the tolerance of Pseudomonas to NP could be as high as $500 \mathrm{mg} / \mathrm{Kg}$. Thus, it is reasonable to infer that Pseudomonas was the predominant degrading bacteria at high NP levels. The relative abundance of some bacterial species decreased with increasing NP concentrations, such as some Proteobacteria (Steroidobacer, Phenylobacterium, Sphingomonas, Methylibium and Lysobacter), Acidobacteria (Holophaga and Geothrix). The relative abundance of Sphingomonas was up to $30 \%$ at low levels of NP, but decreased at high levels of NP. Previous studies reported that Sphingomonas could be isolated from NP contaminated sediments as NP degrading bacteria and those bacteria were considered to use NP as energy and carbon sources ${ }^{27,28}$, suggesting that Sphingomonas might be the dominant degrading bacteria at low NP concentrations. So the genera of Pseudomonas and Sphingomonas were speculated as the predominant degrading bacteria at high and low NP concentrations, respectively. 

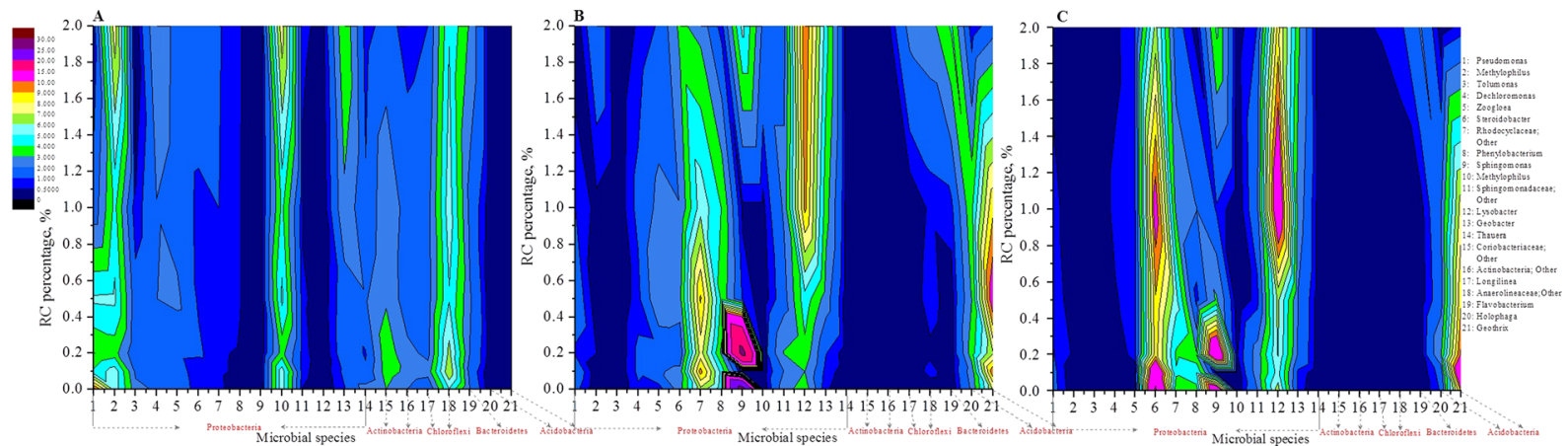

Figure 6. Microbe species (microbial relative abundance) responded with NP concentration and RC percentage. (A) NP concentration was $500 \mathrm{mg} / \mathrm{Kg}$; (B) NP concentration was $50 \mathrm{mg} / \mathrm{Kg}$; (C) NP concentration was $20 \mathrm{mg} / \mathrm{Kg}$.

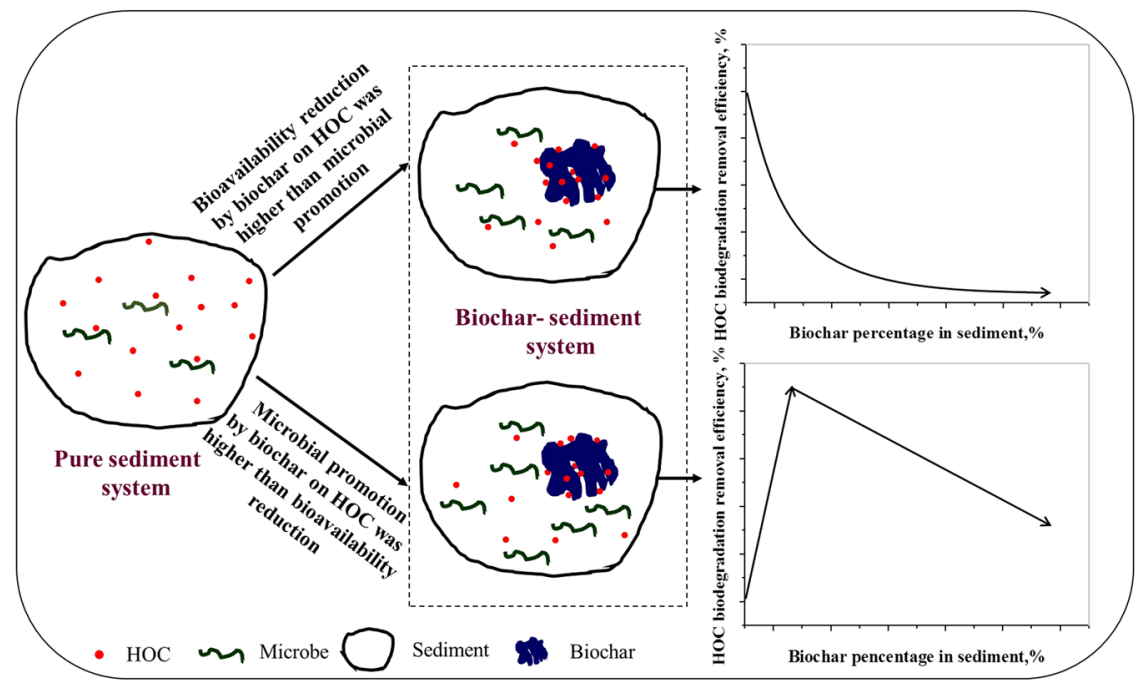

Figure 7. Scheme of role of biochar in NP biodegradation in sediment.

In addition to Pseudomonas and Sphingomonas, bacteria Flavobacterium (Bacteroidetes) and Lysobacter (Gammaproteobacteria) are known for degradation of a variety of phenolic pollutants. Flavobacterium have been linked to degradation of pentachlorophenol and 3-methyl-4-nitrophenol ${ }^{29}$, while Lysobacter species are able to degrade trichlorophenol andpentachlorophenol ${ }^{30}$. Therefore, the presence of Flavobacterium and Lysobacter might have specific roles in NP biodegradation in sediments, which were in line with results of Wang et al. ${ }^{21}$.

Although this study did not demonstrate that the RC amendment impacted the sediment microbial community structure, the relative abundance of some bacterial species, such as Proteobacteria Dechloromonas, Zoogloea, Lysobacter and Geobacter, Chloroflexi Longilinea and Bacteroidetes Flavobacterium increased with RC percentages, respectively. While for some bacteria like Proteobacteria Pseudomonas, Tolumonas and Steroidobacer, their relative abundance decreased with RC percentage. Nonetheless, it was found that for some bacterial species like Proteobacteria Dechloromonas and Zoogloea, Chloroflexi Longilinea and Bacteroidetes Flavobacterium, their relative abundance increased with the increase of both NP concentrations and RC percentages, suggesting that both NP and RC affected those bacterial populations. Unlike the above mentioned bacterial populations, gamma proteobacteria Lysobacter trended to decrease with NP concentrations, but increase with RC percentage, which suggest that high NP concentrations may be toxic to them and/or inhibit their growth, while high RC amendments reduced NP toxicity.

Role of RC in NP biodegradation in sediment. NP biodegradation in RC-sediment system is a comprehensive process, where NP, RC and microorganisms interacted and influenced each other. In this system, adsorption-desorption of NP and microorganisms to RC, microbial growth, and biodegradation of NP exist simultaneously. This study provides a new insight towards the effect of biochar on HOC biodegradation in sediments by studying combined impact of biochar on HOC bioavailability and microorganisms. The difference between impact intense of RC percentages on NP bioavailability and microorganisms determined whether RC reduced or promoted NP biodegradation (Fig. 7). Generally, at low level of NP, high RC amendment reduced NP bioavailability and stimulation of NP towards microorganism, resulting in reducing NP biodegradation. 
When NP concentration was higher than the max stimulating value to microorganism, an appropriate RC dosage amendment reduced NP toxicity to microorganism and promoted microorganism activity. The degree of increasing microbial activity of RC was more than extent of decreasing NP bioavailability and bioaccessibility, resulting in accelerating NP biodegradation. However, increasing microbial activity extent of large dosage RC to microorganism was less than extent of decreasing NP bioavailability and bioaccessibility, resulting in reduction of NP biodegradation. Overall, an appropriate biochar dosage amendment in HOC polluted sediment could form adsorption-biodegradation coupled remediation for organic pollution, which will intensify efficiency of organic pollution remediation.

\section{Conclusions}

This study provides a new insight into effect of RC on NP biodegradation in sediments. Results showed that, the difference between impact of RC on NP bioavailability and microorganisms determined whether RC reduced or promoted NP biodegradation. Furthermore, $\mathrm{RC}$ affected microorganisms by changing NP toxicity and microbial quantity, activity, rather than by changing microbial community structure. This study indicated that there could be an optimal biochar percentage in biochar-sediment systems at different HOC concentrations when biochar was applied for organic pollution control, which strengthened HOC biodegradation process and accelerated biodegradation rate, forming adsorption-biodegradation coupled bioremediation.

\section{Methods}

Chemicals and materials. NP (Mixture of isomers) with a purity of $>99 \%$ was purchased from Aladdin (Shanghai, China) and prepared to generate a concentrated stock solution $(100000 \mathrm{mg} / \mathrm{L})$ with acetonitrile. Sediment was obtained from the Qiantang River, Hangzhou, Zhejiang province, China, using a clam sampler (Juchang Company, Qingdao, Shandong province). The sediment contained $55.01 \%$ of water, its $\mathrm{pH}$ was 7.14 , its cation exchange capacity (CEC) was $10.94 \mathrm{cmol} / \mathrm{kg}$, and its compositions of sand, silt and clay were $7.12 \%$, $13.84 \%$ and $79.04 \%$, respectively. The total organic carbon (TOC) and BC content of the sediment were $0.964 \%$ and $0.37 \%$, respectively. The sediment sample used in this study did not contain a detectable quantity of NP.

The rice straw biochar was prepared from air-dried rice straw collected from the Hua-jia-chi Campus of Zhejiang University in China. The straws were burned on a stainless steel plate in an open field under uncontrolled conditions on a still and sunny afternoon ${ }^{31}$. The sample was treated in $2 \mathrm{M} \mathrm{HCl}$ and $1 \mathrm{M}: 1 \mathrm{M} \mathrm{HCl}-\mathrm{HF}$ solutions to get purified biochar ${ }^{31}$. The treated rice straw biochar was oven-dried overnight at $105^{\circ} \mathrm{C}$, and recorded as RC. The characteristics of RC have been determined before, and are described in our previous work ${ }^{31}$. The sorption isotherms of NP by RC and RC-amended sediments were measured and all the sorption data were fitted well by Freundlich Model. Results indicated that RC posed high sorption capacity to NP with the Freundlich Model capacity factor $K_{F}$ up to $43507.13 \pm 1157.219(\mathrm{mg} / \mathrm{Kg}) /(\mathrm{mg} / \mathrm{L})^{\mathrm{n}}$. Sorption details were described in our previous work ${ }^{32}$.

Biodegradation experiment. The RC-amended sediments were prepared by mixing the sediments and specific quantities of RC to achieve amendment rates of $0 \%, 0.1 \%, 0.2 \% 0.5 \%, 1.0 \%$ and $2.0 \%(\mathrm{w} / \mathrm{w})$. Sterilized Milli-Q water was added to keep same water content of all the samples. The RC-amended sediments were thoroughly mixed before spiking NP and conducting the biodegradation experiments. To assess NP loss by none biodegradation process, the same treated samples used as the controls were processed through sterilization at high temperature $\left(121^{\circ} \mathrm{C}\right)$ and high pressure $(103 \mathrm{kPa}$,) for $20 \mathrm{~min}$, and furthermore in order to inhibit bacterial growth, $0.2 \mathrm{mg} / \mathrm{mL}$ sodium azide $\left(\mathrm{NaN}_{3}\right)$ was added throughout the whole incubation process.

Spiked and incubated experiment. Prior to biodegradation experiment, NP toxicity pre-experiment in sediment, involving in effect of NP toxicity on fluorescein diacetate (FDA) hydrolytic activity and NP biodegradation, was performed using NP concentrations at 20, 50, 100, 200, 500, 1000 and $2000 \mathrm{mg} / \mathrm{Kg}$. Results showed that $230 \mathrm{mg} /$ $\mathrm{Kg}$ in sediment was identified as the NP toxic threshold value to sediment microbes. Considering this threshold together with the NP concentrations of sediments (between several $\mu \mathrm{g} / \mathrm{Kg}$ and hundreds $\mathrm{mg} / \mathrm{Kg}$ dry weight) obtained from the previous investigations ${ }^{33}$, the selected two NP concentration ranges for biodegradation experiment were the concentrations lower than $230 \mathrm{mg} / \mathrm{Kg}(20$ and $50 \mathrm{mg} / \mathrm{Kg})$, which represented actual NP pollution conditions in the sediment, and the concentration higher than $230 \mathrm{mg} / \mathrm{Kg}(500 \mathrm{mg} / \mathrm{Kg})$, which represented acute heavy NP sediment. In order to ensure the same acetonitrile volume in different treatments, NP stock solution $(100000 \mathrm{mg} / \mathrm{L})$ was diluted with acetonitrile into 4000 and $10000 \mathrm{mg} / \mathrm{L}$, respectively. Then $50 \mathrm{~g}$ sterile or nonsterile RC-sediment mixtures were spiked with same volume $(250 \mu \mathrm{L})$ of NP solutions with different concentrations $(4000,10000$ and $100000 \mathrm{mg} / \mathrm{L}$, respectively) to obtain the final concentrations of NP in sediment at 20, 50 and $500 \mathrm{mg} / \mathrm{Kg}$, respectively. After mixing thoroughly, the mixtures in triplicate were incubated in the dark at room temperature for $1,7,14,21,28,42$ and $120 \mathrm{~d}$, respectively.

Extraction and measurement of residual NP concentrations. NP concentrations were measured in aquatic and solid phase at different time intervals. Briefly, $1.0 \mathrm{~g}$ of the mixture was collected in a $50 \mathrm{~mL}$ glass centrifuge tube. $1 \mathrm{~mL}$ Milli Q-water was then added into each tube and vortexed for $1 \mathrm{~min}$. The resultant slurries were centrifuged at $2500 \mathrm{rpm}$ for $20 \mathrm{~min}$. Anhydrous sodium sulfate was added into the glass centrifuge tube to remove residual water after the supernate was poured out. The sediments were extracted after sonication using $5 \mathrm{~mL}$ of methanol:methylbenzene mixture $(6: 1, \mathrm{v} / \mathrm{v})$ in $50 \mathrm{~mL}$ glass centrifuge vials for each sediment sample ${ }^{34,35}$. Sonication was performed for $40 \mathrm{~min}$ using a high-intensity ultrasonic processor (Boston Laboratory Equipment, Woburn, MA) three times. The three extracts from the same sample were combined and concentrated to $1 \mathrm{~mL}$ through nitrogen blowing. 
NP analysis. NP concentrations were analyzed using high performance liquid chromatography (HPLC, Agilent 1100 series) with a diode array fluorescence detector (FLD) and a C18 reversed-phase column (ODS, $5 \mu \mathrm{m}, 2.1$ $\mathrm{mm} \times 250 \mathrm{~mm})$. Acetonitrile and water $(70: 30, \mathrm{v} / \mathrm{v})$ were used as the mobile phase at the flow rate $1.0 \mathrm{~mL} / \mathrm{min}$, and the injection volume was $20 \mu \mathrm{L}$. The FLD wavelengths used for NP were the detection and excitation wavelengths $233 \mathrm{~nm}$ and $302 \mathrm{~nm}$, respectively. The NP concentrations were quantified using an external standard. NP detection limit was about $1 \mu \mathrm{g} / \mathrm{L}$.

Quality control. In the present study, quality control and safety measures were adopted to ensure reliability and validity of the results. First, prior to biodegradation experiment, the organic solvent extraction experiment was carried out to estimate extraction efficiency. Sediment and different RC amendment $(0.5 \%, 1.0 \%, 2.0 \%$ and $5.0 \%)$ samples were extracted by sonication using $5 \mathrm{~mL}$ of methanol:methylbenzene mixture $(6: 1, \mathrm{v} / \mathrm{v})$ across 4 repeated runs, and the NP recovery was $98.68 \pm 3.965,98.13 \pm 2.678,98.77 \pm 1.991,98.39 \pm 2.780$ and $97.62 \pm 2.637 \%$ for sediment, $0.5 \%, 1.0 \%, 2.0 \%$ and $5.0 \% \mathrm{RC}$ amendment, respectively, illustrating the practical effectiveness of the method. Second, the sterile sediment and RC controls were prepared to monitor NP recoveries. The abiotic losses of NP in the controls during the entire period were found less than 5.0\%, which was considered to be negligible.

Microbial toxicity experiment of NP. A luminescent bacterial toxicity testing method was used for aquatic NP toxicity determination ${ }^{36}$. For the test of NP toxicity in sediments, FDA hydrolytic activity assay and NP biodegradation were both used ${ }^{36}$. Briefly, the sediments were spiked with stocked NP to reach the final concentrations of 20,50,100,200,500, 1000 and $2000 \mathrm{mg} / \mathrm{Kg}$, respectively. After that, the sediment samples treated in triplicate were incubated in the dark at room temperature for $14 \mathrm{~d}$. Then, $2.0 \mathrm{~g}$ of the sediments was transferred into $125 \mathrm{~mL}$ Erlenmeyer flasks and $50 \mathrm{~mL}$ of sodium phosphate buffer and $0.50 \mathrm{ml}$ of $4.9 \mathrm{mM}$ FDA lipase substrate solution were added. The flasks were stoppered and swirled for a few seconds and then incubated for $3 \mathrm{~h}$ at $37-38^{\circ} \mathrm{C}$. To terminate FDA hydrolysis, two milliliters of acetone was added to the suspension and they were mixed by swirling flasks. About $30 \mathrm{~mL}$ of the sediment suspension was transfer to a $50 \mathrm{~mL}$ centrifuge tube and centrifuged at $5000 \mathrm{rpm}$ for $5 \mathrm{~min}$, and the supernatant was filtered through a Whatman No. 2 filter paper (ANPEL Scientific Instrument Co., Ltd., Shanghai, China). The filtrate was measured on a spectrophotometer set at a wavelength of $490 \mathrm{~nm}$. To perform controls, the same procedures as described above were performed, but $0.50 \mathrm{~mL}$ acetone, instead of the fluorescein diacetate lipase substrate solution was added to the negative controls. Blanks were also included. The calculation of NP biodegradation ratios was through the extraction of the NP using $5 \mathrm{~mL}$ of methanol:methylbenzene mixture $(6: 1, \mathrm{v} / \mathrm{v})$ in $50 \mathrm{~mL}$ glass centrifuge vials to assess NP toxicity on NP biodegradation.

Microbial quantity, enzymatic activity and community structure. Microbial quantities were estimated using a quantitative PCR (qPCR) method for all bacteria according to the protocol described in previous studies $^{37}$. Briefly, DNA was extracted from approximately $0.25 \mathrm{~g}$ of each sediment sample, with the MoBio Power Soil DNA Isolation Kit. DNA extraction was performed according to the manufacturer's instructions. qPCR was performed using an iCycler iQ5 thermocycler (Bio-Rad, Berkeley, CA) in Personal Biotechnology Co., Ltd., (Shanghai, China). Each qPCR mixture $(25 \mu \mathrm{L})$ was composed of $12.5 \mu \mathrm{L}$ SsoFast EvaGreen Supermix (Bio-Rad, Berkeley, CA), $0.5 \mu \mathrm{L}$ forward and reverse primers, and $1 \mu \mathrm{L}$ template DNA. The qPCR thermal cycle program was performed as previously described ${ }^{38}$. Triplicate reactions of qPCR were performed for each sample and each dilution.

In order to get microbial community structure in sediments with different RC percentages and NP concentrations, 454 pyrosequencing was performed in Personal Biotechnology Co., Ltd., (Shanghai, China) with a set of primers (V3F: 5'-ACTCCTACGGGAGGCAGCAG-3' and V4R: 5'-TACNVGGGTATCTAATCC-3') targeting the hypervariable V3-V4 region (about $460 \mathrm{bp}$ ) of the $16 \mathrm{~S}$ rRNA gene. Equal amounts of purified amplicon products bearing individual 10 nucleotide barcodes from different samples were mixed for pyrosequencing on the Roche 454 FLX Titanium platform (Roche Diagnostics, Indianapolis, IN). The sequences were analyzed using the method described previously by Hao et al. ${ }^{39}$. Operational taxonomic unit (OTU), rarefaction curves and the diversity indices were determined using Mothur (www.mothur.org) and the taxonomy-based analysis was conducted using RDP-II Classifier of the Ribosomal Database Project (RDP) and the National Center for Biotechnology Information (NCBI) BLAST.

Data analysis. SPS for windows (Version 13.0) was used to statistically analyze NP biodegradation data. One-way ANOVA was applied to test difference of NP biodegradation data among different RC amendments with a $95 \%$ confidence level or $\alpha=0.05$.

NP biodegradation data fitted. Pseudo first order kinetics model was applied to fit NP biodegradation curves. The formula was as follows:

$$
F_{t}=F_{d e}+F_{d e} \exp \left(-k_{a v e} t\right)
$$

Where $F_{\mathrm{t}}$ represents residual NP amount in RC-sediment system at time $\mathrm{t}, \% ; F_{\mathrm{de}}$ represents biodegraded NP amount in RC-sediment system, $\% ; k_{\text {ave }}$ represents NP average biodegradation rate constant, $\% / \mathrm{d}$.

The half-life period of NP in a RC-sediment system was calculated by the following formula:

$$
t_{1 / 2}=\ln 2 / k_{\text {ave }}
$$

Where $t_{1 / 2}$ represents half-life of NP in RC-sediment system, $\mathrm{d}$. 
Concentration Suppression Curve of NP. FDA hydrolytic activity and the ratios of NP biodegradation were plotted against time $(\mathrm{t})$ and the Haldane model was fitted to the data, as follows:

$$
\begin{gathered}
V=V_{\max } /\left(1+K_{\mathrm{m}} / S+S / K_{\mathrm{i}}\right) \\
S_{\max }=\sqrt{K m K i}
\end{gathered}
$$

Where $V$ represents the substrate reaction rate (instead of fluorescein concentration $(\mathrm{mg} / \mathrm{g})$ or NP biodegradation ratio (\%) in this study); $V_{\max }$ represents the fastest reaction rate (the highest fluorescein concentration $(\mathrm{mg} / \mathrm{g}$ ) or NP biodegradation ratio (\%) in this study); $K_{\mathrm{m}}$ represents the half rate constant; $K_{\mathrm{i}}$ represents the inhibition constant; $S$ is the substrate concentration, $\mathrm{mg} / \mathrm{Kg} ; S_{\max }$ is the corresponding NP concentration to the highest fluorescein concentration or NP biodegradation ratio, $\mathrm{mg} / \mathrm{Kg}$.

Data Availability. All data generated or analysed during this study are included in this published article (and its Supplementary Information files).

\section{References}

1. Cornelissen, G. \& Gustafsson, Ö. Sorption of phenanthrene to environmental black carbon in sediment with and without organic matter and native sorbates. Environ. Sci. Technol. 38, 148-155 (2003).

2. Cornelissen, G. et al. Extensive sorption of organic compounds to black carbon, coal and kerogen in sediments and soils: mechanisms and consequences for distribution, bioaccumulation and biodegradation (critical review). Environ. Sci. Technol. 39, 6881-6895 (2005).

3. Rhodes, A. H., Carlin, A. \& Semple, K. T. Impact of black carbon in the extraction and mineralization of phenanthrene in soil. Environ. Sci. Technol. 42, 740-745 (2008).

4. Yang, Y., Hunter, W., Tao, S., Crowley, D. \& Gan, J. Effect of activated carbon on microbial bioavailability of phenanthrene in soils. Environ. Toxicol. Chem. 28, 2283-2288 (2009).

5. Rhodes, A. H., Riding, M. J., McAllister, L. E., Lee, K. \& Semple, K. T. Influence of activated charcoal on desorption kinetics and biodegradation of phenanthrene in soil. Environ. Sci. Technol. 46, 12445-12451 (2012).

6. Sopeña, F., Semple, K., Sohi, S. \& Bending, G. D. Assessing the chemical and biological accessibility of the herbicide isoproturon in soil amended with biochar. Chemosphere 88, 77-83 (2012).

7. Bunemann, E. K., Schwenke, G. D. \& Van Zwieten, L. Impact of agricultural inputs on soil organisms-a review. Aust. J. Soil Res. 44, 379-406 (2006).

8. Lehmann, J. et al. Biochar effects on soil biota - a review. Soil Biol. Biochem. 43, 1812-1836 (2011).

9. Meynet, P. et al. Effect of activated carbon amendment on bacterial community structure and functions in a PAH impacted urban soil. Environ. Sci. Technol. 46, 5057-5066 (2012).

10. Vasilyeva, G.K., Strijakova, E.R., Shea, P.J. Use of activated carbon for soil bioremediation. Soil and water pollution monitoring, protection and remediation. 309-322 (Springer Netherlands, 2006).

11. Bushnaf, K. M., Puricelli, S., Saponaro, S. \& Werner, D. Effect of biochar on the fate of volatile petroleum hydrocarbons in an aerobic sandy soil. J. Contam. Hydrol. 126, 208-215 (2011).

12. Semple, K. T., Morriss, A. W. J. \& Paton, G. I. Bioavailability of hydrophobic organic contaminants in soils: fundamental concepts and techniques for analysis. Eur. J. Soil Sci. 54, 809-818 (2003).

13. Ghosh, U., Luthy, R. G., Cornelissen, G., Werner, D. \& Menzie, C. A. In-situ sorbent amendments: a new direction in contaminated sediment management. Environ. Sci. Technol. 45, 1163-1168 (2011).

14. Wu, Y. et al. Quantitative relationship between cadmium uptake and the kinetics of phytochelatin induction by cadmium in a marine diatom. Sci. Rep. 6 (2016).

15. Xu, D. F. et al. The forms and bioavailability of phosphorus in integrated vertical flow constructed wetland with earthworms and different substrates. Chemosphere 134, 492-498 (2015).

16. Semple, K. T. et al. Defining bioavailability and bioaccessibility of contaminated soil and sediment is complicated. Environ. Sci. Technol. 38, 228A-231A (2004).

17. Cui, X. Y., Bao, L. J. \& Gan, J. Solid-phase microextraction (SPME) with stable isotope calibration for measuring bioavailability of hydrophobic organic contaminants. Environ. Sci. Technol. 47, 9833-9840 (2013).

18. Cui, X. Y., Mayer, P. \& Gan, J. Methods to assess bioavailability of hydrophobic organic contaminants: Principles, operations, and limitations. Environ. Pollut. 172C, 223-234 (2012).

19. Stenrad, M., Klemsdal, S. S., Norli, H. R. \& Eklo, O. M. Effects of picoxystrobin and 4-n-nonylphenol on soil microbial community structure and respiration activity. Plos One 8, 1475-1478 (2013).

20. Jontofsohn, M. et al. Influence of nonylphenol on the microbial community of lake sediments in microcosms. Sci. Total Environ. 285, 3-10 (2002).

21. Wang, Z., Yang, Y., Sun, W., Xie, S. \& Liu, Y. Nonylphenol biodegradation in river sediment and associated shifts in community structures of bacteria and ammonia-oxidizing microorganisms. Ecotox. Environ. Safe 106, 1-5 (2014).

22. Anderson, C. R. et al. Biochar induced soil microbial community change: Implications for biogeochemical cycling of carbon, nitrogen and phosphorus. Pedobiologia 54, 309-320 (2011).

23. Khodadad, C. L. M., Zimmerman, A. R., Green, S. J., Uthandi, S. \& Foster, J. S. Taxa-specific changes in soil microbial community composition induced by pyrogenic carbon amendments. Soil Biol. Biochem. 43, 385-392 (2011).

24. Tong, H., Hu, M., Li, F. B., Liu, C. S. \& Chen, M. J. Biochar enhances the microbial and chemical transformation of pentachlorophenol in paddy soil. Soil Biol. Biochem. 70, 142-150 (2014).

25. Yuan, S. Y., Yu, C. H. \& Chang, B. V. Biodegradation of nonylphenol in river sediment. Environ. Pollut. 127, 425-430 (2004).

26. Watanabe, W., Hori, Y., Nishimura, S., Takagi, A. \& Kikuchi, M. Bacterial degradation and reduction in the estrogen activity of 4-nonylphenol. Biocontrol Sci. 17, 143-147 (2012).

27. Fujii, K., Urano, N., Ushio, H., Satomi, M. \& Kimura, S. Sphingomonas cloacae sp. nov., a nonylphenol-degrading bacterium isolated from wastewater of a sewage-treatment plant in Tokyo. Int. J. Syst. Evol. Micr. 51, 603-610 (2001).

28. Corvini, P. F. X. et al. Metabolism of a nonylphenol isomer by Sphingomonassp. strain TTNP3. Environ. Chem. Lett. 2, 185-189 (2005).

29. $\mathrm{Pu}, \mathrm{X}$. C. \& Cutright, T. J. Degradation of pentachlorophenol by pure and mixed cultures in two different soils. Environ. Sci. Pollut. Res. 14, 244-250 (2007).

30. Caliz, J. et al. The microbiota of an unpolluted calcareous soil faces up chlorophenols: Evidences of resistant strains with potential for bioremediation. Chemosphere 83, 104-116 (2011).

31. Lou, L. P. et al. The sorption of pentachlorophenol by aged sediment supplemented with black carbon produced from rice straw and fly ash. Bioresource Technol. 112, 61-66 (2012) 
32. Lou, L. P. et al. Mechanism and relationship and between adsorption and desorption of nonylphenol on black carbon-inclusive sediment. Environ. Pollut. 190, 101-108 (2014).

33. Mao, Z. et al. Occurrence and biodegradation of nonylphenol in the environment. Int. J. Mol. Sci. 13(1), 491-505 (2012).

34. García-Delgado, C., Alfaro-Barta, I. \& Eymar, E. Combination of biochar amendment and mycoremediation forpolycyclic aromatic hydrocarbons immobilization and biodegradation in creosote-contaminated soil. J. Hazard. Mater. 285, 259-266 (2015).

35. Gámiz, B., Cox, L., Hermosín, M. C., Spokas, K. \& Celis, R. Assessing the effect of organoclays and biochar on the fate of abscisic acid in soil. J. Agric. Food Chem. 65, 29-38 (2017).

36. Jurado, E., Fernández-Serrano, M., Núñez-Olea, J., Luzón, G. \& Lechuga, M. Acute toxicity and relationship between metabolites and ecotoxicity during the biodegradation process of non-ionic surfactants: fatty-alcohol ethoxylates, nonylphenol polyethoxylate and alkylpolyglucosides. Water Sci. Technol. 59, 2351-2358 (2009).

37. Shen, L. D. et al. Broad distribution of diverse anaerobic ammonium-oxidizing bacteria in chinese agricultural soils. Appl. Environ. Microbiol. 79, 6167-6172 (2013).

38. Harhangi, H. R. et al. Hydrazine synthase, a unique phylomarker with which to study the presence and biodiversity of anammox bacteria. Appl. Environ. Microbiol. 78, 752-758 (2012).

39. Hao, T. et al. Characterization of sulfate-reducing granular sludge in the SANI ${ }^{\circledR}$ process. Water. Res. 47, 7042-7052 (2013).

\section{Acknowledgements}

This research is financially supported by the National Natural Science Foundation of China (41371447 and 41371320), Jiangsu Natural Science Foundation (BK20150042) and Significant Research Plan of NSFC (91543115). It has been subjected to the review of the United States Environmental Protection Agency through its Office of Research and Development and approved for publication. Mention of trade names or commercial products does not constitute endorsement or recommendation for use.

\section{Author Contributions}

G.H.C. and L.P.L. designed the experiments. G.H.C. developed methods for measuring and detecting NP in water and sediment, performed and interpreted the data of NP biodegradation and NP toxicity experiment, and wrote the manuscript. M.Y.S. designed, performed and interpreted the data of the microbial quantity and enzymatic activity experiments. J.R.L. designed, performed and interpreted the data of community structure experiments and modified language of the manuscript. X.L.G. reviewed the manuscript and modified language of the manuscript. H.H.Z. adjusted format of the manuscript. X.H.X. discussed results and reviewed the manuscript. Q.L. modified language of the manuscript.

\section{Additional Information}

Supplementary information accompanies this paper at doi:10.1038/s41598-017-04787-2

Competing Interests: The authors declare that they have no competing interests.

Publisher's note: Springer Nature remains neutral with regard to jurisdictional claims in published maps and institutional affiliations.

(c) (i) Open Access This article is licensed under a Creative Commons Attribution 4.0 International C. License, which permits use, sharing, adaptation, distribution and reproduction in any medium or format, as long as you give appropriate credit to the original author(s) and the source, provide a link to the Creative Commons license, and indicate if changes were made. The images or other third party material in this article are included in the article's Creative Commons license, unless indicated otherwise in a credit line to the material. If material is not included in the article's Creative Commons license and your intended use is not permitted by statutory regulation or exceeds the permitted use, you will need to obtain permission directly from the copyright holder. To view a copy of this license, visit http://creativecommons.org/licenses/by/4.0/.

(C) The Author(s) 2017 